\title{
Endogenous Carbon Monoxide Production in Patients with Hemolytic Anemia*
}

\author{
R. F. Coburn, $†$ W. J. Williams, $\ddagger$ and S. B. Kahn $\S$ \\ (From the Departments of Physiology, Graduate Division, and Medicine, School of Medicine, \\ University of Pennsylvania, Philadelphia, Pa.)
}

It is desirable in many studies to be able to rapidly measure rates of erythrocyte and hemoglobin destruction. Labeling techniques have been utilized for this purpose but have the disadvantage of requiring several days to weeks to obtain the desired data plus the hazards of radioactive isotopes. Estimations of hemoglobin turnover from measurements of fecal bile pigment or serum bilirubin concentrations contain large sources of error (1). Studies in which bile pigment is collected via bile duct fistulas have been of value in animal experiments (2) but are not usually possible in man, and subjects who have bile fistulas cannot be called normal. At the present time it appears that many in vivo investigations of red cell survival in patients with hemolytic disease are limited by the lack of a precise rapid method for detecting changes in the rate of red cell destruction.

It has been shown previously (3-9) that $\mathrm{CO}$ is an in vivo catabolic by-product of hemoglobin and

\footnotetext{
* Submitted for publication May 10, 1965 ; accepted December 9, 1965.

Presented in part at the Annual Meeting of the American Society for Clinical Investigation in Atlantic City, N. J., May 1963, and abstracted in J. clin. Invest. 1963, 42, 924.

Supported in part by a grant from the Life Insurance Medical Research Fund and grant 3 M 01 FR-40-05 from the Clinical Research Center, National Institutes of Health, Bethesda, Md.

$\dagger$ Former postdoctoral research fellow of the National Institutes of Health. Recipient of U. S. Public Health Service Research Career Program Award 1-K3-HE-11,564-01 from the National Heart Institute.

Address requests for reprints to Dr. Ronald F. Coburn, Dept. of Physiology, Graduate Division, School of Medicine, University of Pennsylvania, Philadelphia, Pa. 19104.

$\ddagger$ Recipient of U. S. Public Health Service Research Career Program Award IHE-K3 2629 from the National Heart Institute.

\$ Trainee in hematology under training grant TI-AM5228 from the National Institute of Arthritis and Metabolic Diseases.
}

that it probably originates from the heme $\alpha$-methine bridge carbon atom. Data obtained in experiments where $\mathrm{CO}$ production was measured after intravenous injections of suspensions of damaged erythrocytes or solutions of hemoglobin have indicated that the molar yield of $\mathrm{CO}$ produced to heme catabolized is approximately unity in normal man (6) and anesthetized dogs (9). Apparently, therefore, the measurement of $\mathrm{CO}$ production is useful in studying hemoglobin and red cell turnover and can be utilized in studies of patients with increased erythrocyte destruction. The quantitation of erythrocyte and hemoglobin catabolism from $\mathrm{CO}$ production measurements has the advantages that it is rapidly accomplished, does not require isotopes, and can be repeated.

Early workers $(4,10)$ attempted to estimate red cell survival with measurements of the venous blood carboxyhemoglobin per cent saturation ([COHb]) in patients with hemolytic anemia; this approach seems inadequate in view of the uncertainties of the relationship of $[\mathrm{COHb}]$ to the actual rate of $\mathrm{CO}$ production in these patients (11). The development of a method of estimating the rate of $\mathrm{CO}$ production ( $\mathrm{V} \mathrm{CO}$ ) based on the measurement of the rate of increase in $\mathrm{CO}$ body stores under conditions where $\mathrm{CO}$ excretion from the body is prevented by having the subject rebreathe in a closed system has apparently circumvented this difficulty (5).

In the present report we describe a modification of the rebreathing system that has allowed us to measure Vco in seriously ill and debilitated patients. With this system Vco has been determined in seven patients with hemolytic anemia. The results show that the measurement can be used to quantitate erythrocyte and hemoglobin destruction in these patients and that there is a fraction of the $V$ co that apparently cannot be explained on the basis of catabolism of circulating hemoglobin. 

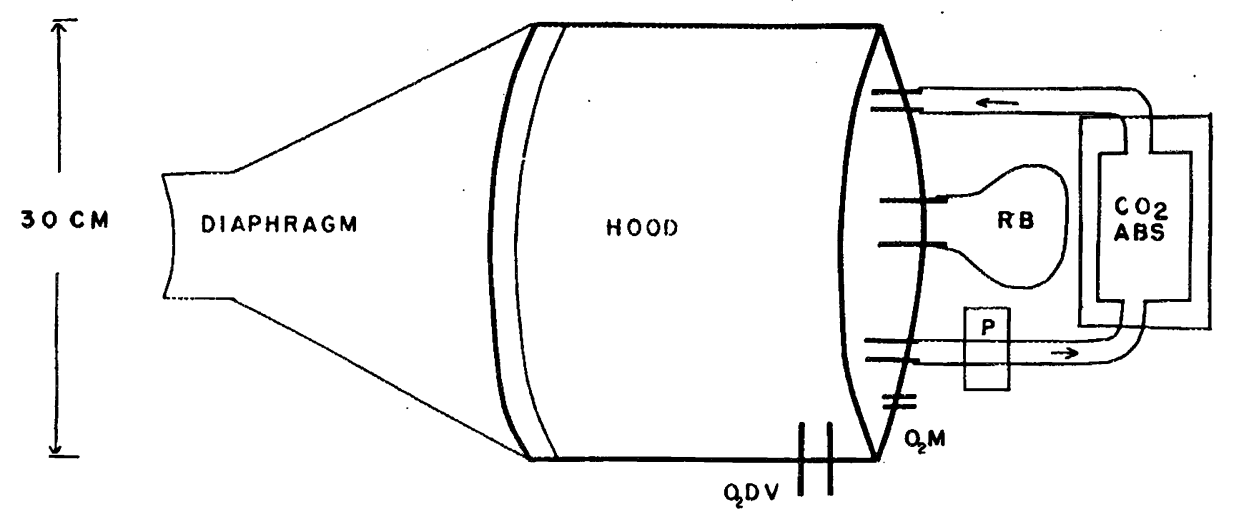

$30 \mathrm{CM}$

1

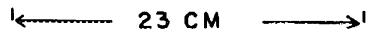

Fig. 1. Scirematic Representation of the rebreathing system. The hood, diaphragm, and pumping system are shown. $\mathrm{RB}$, rubber bag; $\mathrm{CO}_{2} \mathrm{ABS}$, carbon dioxide absorber; $\mathrm{P}$, pump; $\mathrm{O}_{2} \mathrm{M}$, oxygen meter; $\mathrm{O}_{2} \mathrm{DV}$, oxygen demand valve.

\section{Methods}

$C O$ production measurements. The rate of $\mathrm{CO}$ production was determined by the rebreathing method described in detail in a previous publication (5), except that the apparatus used was modified so that the subject breathed in a plastic hood rather than through a mouthpiece. The studies were performed with the $\mathrm{O}_{2}$ tension in the hood and rebreathing system adjusted to approximately $150 \mathrm{~mm} \mathrm{Hg}$. The first venous blood sample was drawn at least 15 minutes after the start of rebreathing; additional samples were taken every 30 minutes for a total of 2 hours. After this the body $\mathrm{CO}$ dilution was determined by adding $10 \mathrm{ml}$ of $\mathrm{CO}$ to the rebreathing system and measuring the resultant increase in $[\mathrm{COHb}$. Blood [COHb] was measured with an infrared $\mathrm{CO}$ method (12), the rate of increase in [COHb] was determined graphically, and the Vco was calculated from this value and the $\mathrm{CO}$ blood volume or $\mathrm{CO}$ dilution in the body (5). The error in the Vco measurement is $\pm 3.1 \mu$ moles per hour (SD) (5). This method assumes rapid mixing and èquilibration of endogenously produced $\mathrm{CO}$ and $\mathrm{CO}$ added at the end of each experiment in the blood and extravascular $\mathrm{CO}$ stores, which include $\mathrm{CO}$ bound in muscle, liver, bone marrow, and possibly other organs (5). The available data regarding equilibration and mixing of the body $\mathrm{CO}$ stores have been reviewed previously (5). These data and unpublished data obtained in our laboratory (13) indicate that for the purposes of the VCo measurement the body $\mathrm{CO}$ stores can be assumed to be a single rapidly equilibrating "pool" without the introduction of significant error. The hemolytic patients studied in the present investigation presumably had more bone marrow than normal man, and it secms likely that the portion of the body $\mathrm{CO}$ stores present in this tissue would be greater. The marrow is, however, a vascular structure, and it would be expected that marrow $\mathrm{CO}$, like other extravascular $\mathrm{CO}$ stores, would equilibrate rapidly with intravascular
$\mathrm{CO}$ and that this larger marrow $\mathrm{CO}$ pool would not cause significant crror in the Vco measurement.

The rebreathing system. We have modified the rebreathing system used in our previous investigations so that the subject does not have to breathe through a mouthpiece and wear a noseclip but rather breathes in a plastic hood that fits over the head and is sealed about the neck with a rubber diaphragm (Figure 1). A pump constantly circulates the gas in the hood through a $\mathrm{CO}_{2}$ absorber and cooler. The hood is made of $\frac{1}{2}-\mathrm{cm}$ plastic and has the shape of a cylinder closed at one end. The outside diameter of the cylinder is $30 \mathrm{~cm}$, and it is 23 $\mathrm{cm}$ in length. Five gas taps lead into the hood. Two of these are $3 \mathrm{~cm}$ in diameter and are used in pumping gas to and from the $\mathrm{CO}_{2}$ absorber and cooler. A tap 1 $\mathrm{cm}$ in diameter leads to the oxygen meter. The fourth tap, $4 \mathrm{~cm}$ in diameter, is connected to a rubber bag that is used as a gas reservoir. The fifth tap is connected to an oxygen demand valve adjusted so that oxygen is added to the system at the end of each inspiration. The patient's neck is greased with silicone grease before fitting of the diaphragm to improve the seal between the neck and hood. We have diaphragms ${ }^{\perp}$ for varying neck sizes, and it has been possible to achieve a tight seal in all patients without neck constriction. The air pump ${ }^{2}$ used in the system has a maximal flow through our system of 60 $\mathrm{L}$ per minute. The canister contains approximately $800 \mathrm{ml}$ of $\mathrm{CO}_{2}$ absorbant ${ }^{3}$ and is placed in an insulated container filled with ice. The air flow through the $\mathrm{CO}_{2}$ absorber is sufficient to keep the $\mathrm{CO}_{3}$ in the system below $0.5 \%$. The apparatus as described has a total gas volume of approximately $7 \mathrm{~L}$ (with head in hood and $\mathrm{CO}_{2}$ canister filled with Baralyme). The volume of the apparatus plus

${ }^{1}$ Made by Stockwell Rubber Co., Philadelphia, Pa.

2 Collins motor blower, catalogue no. P-553, Warren E. Collins, Inc., Boston, Mass.

3 Baralyme granules, National Cylinder Gas Co., Chicago, III. 


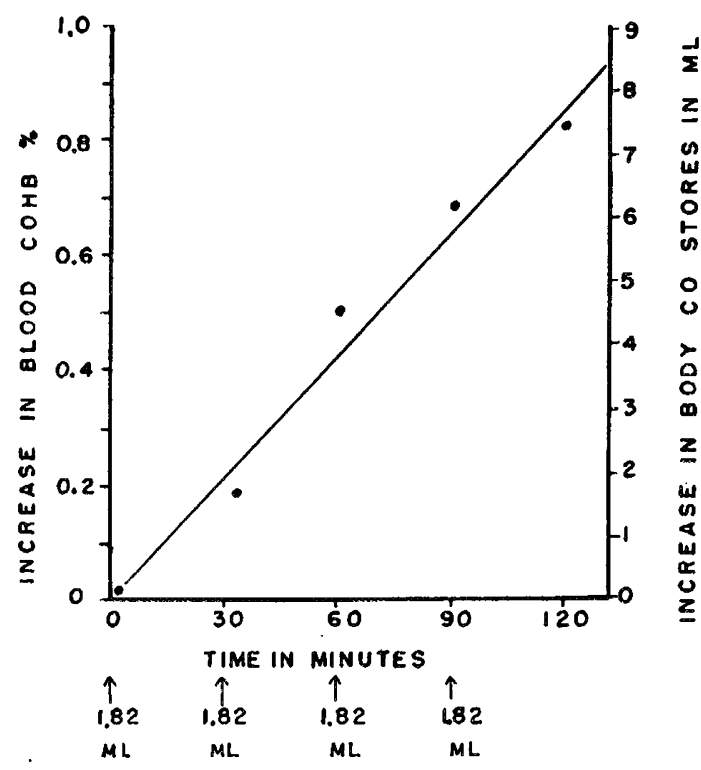

Fig. 2. Simulated CO production in a nokmal. male SUBJECT. Endogenous CO production was "simulated" by adding $\mathrm{CO}$ to the rebreathing system every 30 minutes for 2 hours. The "rate of CO production" was determined in the usual manner by measuring the rate of increase in blood carboxyhemoglobin per cent saturation and calculating the rate of increase in the body $\mathrm{CO}$ stores. In this experiment $3.64 \mathrm{ml} \mathrm{CO}$ per hour was added. The measured rate of $\mathrm{CO}$ increase in the body was $4.00 \mathrm{ml}$ per hour. The difference is entirely explainable by endogenous $\mathrm{CO}$ production.

lung volume is approximately $12 \mathrm{~L}$. In designing this system we kept the volume as small as possible to minimize $\mathrm{CO}$ loss from the body into gas, which occurs as $[\mathrm{COHb}]$ increases during the procedure. The $\mathrm{CO}$ loss that could occur in our system from this process is less than $0.02 \mu$ mole per hour in a normal subject.
During most of the studies we checked the system for leaks by injecting small quantities of neon into the gas in the rebreathing system and monitoring the neon concentration in this gas with a gas chromatograph. In all of the studies the neon concentration decreased slightly during the first 30 minutes and then remained constant during the remainder of the study. The initial decrease in neon concentration presumably resulted from wash-in of neon into the lungs and solubility in body tissues rather than leakage out of the system. Although the system proved to be free of leaks, the Vco measurement is not highly sensitive to leaks. A leak of $1 \mathrm{~L}$ out of the system in 2 hours would cause an error of less than 0.5 $\mu$ mole per hour in measured Vco in a normal subject; leaks into the system would result in proportionately smaller error, since the $\mathrm{CO}$ concentration in room air is usually less than in the equilibrated air in the rebreathing system.

Simulated $C O$ production experimenits. We performed two experiments designed to measure the precision of the rebreathing method and determine if the precision of $\pm 3.1 \mu$ moles per hour (SD) ( $0.07 \mathrm{ml}$ per hour) could be achieved when VCo was elevated. A known amount of $\mathrm{CO}$ was periodically added to the body stores by injecting $\mathrm{CO}$ into the rebreathing gas. The rate of $\mathrm{CO}$ injection was compared with the measured Vco calculated from the rate of increase in [COHb]. Data from an experiment performed on a normal male subject are shown in Figure 2. The patient initiated breathing in the closed system. A venous blood sample was drawn, and $1.82 \mathrm{ml}$ (standard temperature and pressure, dry) of $\mathrm{CO}$ was added to the rebreathing system. This sequence was repeated every 30 minutes so that $3.64 \mathrm{ml}$ of $\mathrm{CO}$ was added per hour to the body stores. Measured VCo was $4.00 \mathrm{ml}$ per hour. The difference between the simulated Vco and measured Vco was $0.36 \mathrm{ml}$ per hour and is entirely explainable on the basis of normal endogenous $\mathrm{CO}$ production. The $\mathrm{V} c \mathrm{C}$ in normal young male subjects averages $0.42(\mathrm{SD} \pm 0.07) \mathrm{ml}$ per hour (5). The second experiment was performed on an anesthetized dog breathing in a closed system. Simulated

TABLE I

Pertinent indexes

\begin{tabular}{|c|c|c|c|c|c|c|c|c|}
\hline & Patient & $\begin{array}{l}\text { Age } \\
\text { Sex }\end{array}$ & Height & Weight: & Diagnosis & $\begin{array}{l}\text { Total body } \\
\text { hemoglobin }\end{array}$ & ${ }_{\mathrm{t}}^{\mathrm{m}}$ & $\mathbf{K}^{\prime *}$ \\
\hline & & years & inches & pounds & & $g$ & days & $\% / d a y$ \\
\hline & BS & $16 \mathrm{~F}$ & 59 & 88 & Aútoimmune: & 196 & 4.7 & 13.41 \\
\hline & $\mathrm{HM}$ & $22 \mathrm{M}$ & 67 & 170 & S-St & 518 & 6.8 & 8.99 \\
\hline . & $\mathrm{GH} f$ & $22 \mathrm{~F}$ & 61 & 109 & $\mathbf{S}-\mathbf{S}$ & 235 & 7.0 & 8.61 \\
\hline & $\mathrm{MC}^{+}$ & $62 \mathrm{~F}$ & 65 & 144 & Autoimmune & 349 & 18 & 2.55 \\
\hline & $\mathrm{FS}$ & $25 \mathrm{M}$ & 72 & 137 & Hodgkin's disease & 467 & 22 & 1.84 \\
\hline & $\mathrm{FS}_{2} \ddagger$ & $26 \mathrm{M}$ & 72 & 141 & Hodgkin's disease & 306 & 15 & 3.31 \\
\hline & $\mathrm{CJ}+$ & $21 \mathrm{M}$ & 70 & 159 & S-S & 621 & 16 & 3.13 \\
\hline & IBt & $23 \mathrm{M}$ & 68 & 131 & S-S & 430 & 7 & 8.61 \\
\hline
\end{tabular}

* $\mathrm{K}^{\prime}$, the measured decay in blood ${ }^{1} \mathrm{Cr}$ minus correction for elution of $1.29 \%$ per day.

$+\mathrm{S}-\mathrm{S}$, sickle cell anemia.

In these patients we measured serum folic acid (17) and urine formiminoglutamic and urocanic acids after a histidine load (18). Normal values were found in $\mathrm{GH}, \mathrm{FS}_{2}$, and $\mathrm{CJ}$. IB had slightly decreased serum folic acid level and slightly increased urine formiminoglutamic and urocanic acid levels. 
TABLE II

CO production and hemoglobin destruction data*

\begin{tabular}{|c|c|c|c|c|c|c|}
\hline Patient & Date & $\begin{array}{c}\text { Rate } \\
\text { increase } \\
\text { [COHb] }\end{array}$ & {$[\mathrm{COHb}]$} & $\dot{\text { V̇co }}$ & V̀heme & $\dot{\text { V́co/V̈heme }}$ \\
\hline & & $\% / h r$ & $\underset{\text { ration }}{\% \text { satu- }}$ & $\mu$ moles $/ h r$ & $\mu$ moles $/ h r$ & $\mu$ moles $/ h r / \mu m o l e / h r$ \\
\hline BS & $10-23-61$ & 0.56 & 2.62 & 72 & 65 & 1.10 \\
\hline HM & $\begin{array}{l}4-19-62 \\
4-20-62\end{array}$ & $\begin{array}{l}0.36 \\
0.36\end{array}$ & $\begin{array}{l}2.46 \\
2.33\end{array}$ & $\begin{array}{l}115 \\
109\end{array}$ & 114 & 0.99 \\
\hline GH & $\begin{array}{r}7-9-62 \\
7-11-62\end{array}$ & $\begin{array}{l}0.42 \\
0.51\end{array}$ & $\begin{array}{l}2.24 \\
1.71\end{array}$ & $\begin{array}{l}62 \\
68\end{array}$ & 49 & 1.32 \\
\hline MC & $1-9-62$ & 0.15 & 1.34 & 31 & 22 & 1.41 \\
\hline $\mathrm{FS}_{1}$ & $\begin{array}{l}5-14-62 \\
5-16-62\end{array}$ & $\begin{array}{l}0.11 \\
0.13\end{array}$ & $\begin{array}{l}0.81 \\
0.77\end{array}$ & $\begin{array}{l}32 \\
35\end{array}$ & 21 & 1.62 \\
\hline $\mathrm{FS}_{2}$ & $10-20-62$ & 0.26 & 2.47 & 48 & 25 & 1.92 \\
\hline GJ & $\begin{array}{l}9-10-62 \\
9-12-62\end{array}$ & $\begin{array}{l}0.16 \\
0.18\end{array}$ & $\begin{array}{l}1.46 \\
1.85\end{array}$ & $\begin{array}{l}62 \\
64\end{array}$ & 47 & 1.33 \\
\hline IB & $\begin{array}{l}12-11-62 \\
12-13-62\end{array}$ & $\begin{array}{l}0.53 \\
0.58\end{array}$ & $\begin{array}{l}2.10 \\
2.12\end{array}$ & $\begin{array}{l}138 \\
143\end{array}$ & 91 & 1.54 \\
\hline $\begin{array}{l}\text { Average } \\
\text { Normal }\end{array}$ & & 0.05 & 0.88 & 18.7 & 14.7 & $\begin{array}{l}1.40 \pm(\mathrm{SE}) 0.10 \\
1.27 \pm(\mathrm{SE}) 0.08\end{array}$ \\
\hline
\end{tabular}

* [COHb], venous blood carboxyhemoglobin; $\dot{\mathrm{V}} \mathrm{CO}$, rate of $\mathrm{CO}$ production; $\dot{\mathrm{V} h e m e, ~ r a t e ~ o f ~ b l o o d ~ h e m e ~ c a t a b o l i s m . ~}$

Vco was again $3.64 \mathrm{ml}$ per hour, and measured Vco was $3.70 \mathrm{ml}$ per hour. The average endogenous Vco found in anesthetized dogs is $0.18(\mathrm{SD} \pm 0.08) \mathrm{ml}$ per hour (9). These experimental results suggest that the precision of the measurement is similar with normal and markedly elevated Vco.

Measurement of erythrocyte and hemoglobin destruction rates. Erythrocyte survival studies were performed with radiochromate by the method of Read (14) except that acid-citrate-dextrose anticoagulant was used. The method was then nearly identical to that of Cline and Berlin (15). These data were expressed as a half-time, $t_{\frac{1}{3}}$, the time at which blood radioactivity reached $50 \%$ of the initial value. From this we calculated the time constant, $\mathrm{K}$, using the following equation which assumes that erythrocyte destruction was random: $N=N_{0} e^{-\mathbf{k t}}$. $\mathrm{N}_{0}$ is the initial red cell radioactivity at zero time, $\mathrm{N}$ the radioactivity at time $t$, and $K$ the time constant in per cent per day. $\mathrm{K}$ was corrected for elution, assuming this process is constant and exponential and equal to $1.29 \%$ per day (15) giving a corrected time constant $\mathrm{K}^{\prime}$. The rate of blood heme destruction was calculated by multiplying $\mathrm{K}^{\prime}$ and the total body hemoglobin calculated from the $\mathrm{CO}$ dilution measurements (16). The results are expressed as micromoles heme destroyed per hour.

The patients used in this study had documented hemolytic diseases. Vital statistics and diagnoses are listed in Table I. All of the patients were thought to be clinically in a stable or steady state. Five of the seven patients were brought into the hospital specifically for this study. Drug regimens were not changed during the study period. None of the patients had been transfused for 3 months before the study. One of the patients (FS) was studied completely at two different stages of his disease (May and November of 1962). Three of the patients (BS, FS, and CJ), were smokers but were not allowed to smoke for 2 days before the Vco measurements; the remainder of the patients denied smoking.

\section{Results}

Total body hemoglobin, ${ }^{51} \mathrm{Cr} \mathrm{t}_{\frac{1}{2}}$, and calculated $\mathrm{K}^{\prime}$ values are listed for each patient in Table $\mathrm{I}$. The $\mathrm{t}_{\mathrm{f}}$ of ${ }^{51} \mathrm{Cr}$ varied from 4.7 to 22 days; $\mathrm{K}^{\prime}$ ranged from 1.84 to $13.41 \%$ per day. Calculated values of Vheme are listed in Table II. These were found to range from 21 to $114 \mu$ moles per hour, or 0.36 to $1.94 \mathrm{~g}$ hemoglobin per hour. The rates of blood hemoglobin catabolism were, therefore, approximately $1 \frac{1}{2}$ to 8 times the normal value of $14.7 \mu$ moles per hour.

Table II shows the data on $\mathrm{CO}$ production in these patients. The venous blood $[\mathrm{COHb}]$ of the first sample drawn in each study was greater than normal in seven of the eight studies, ranging from 0.77 to $2.62 \%$. The average [COHb] in patients without hemolytic disease is $0.88 \pm 0.11 \%$ (SD) (12). Vco was elevated compared to normal in all of the patients. The range of values was 0.70 

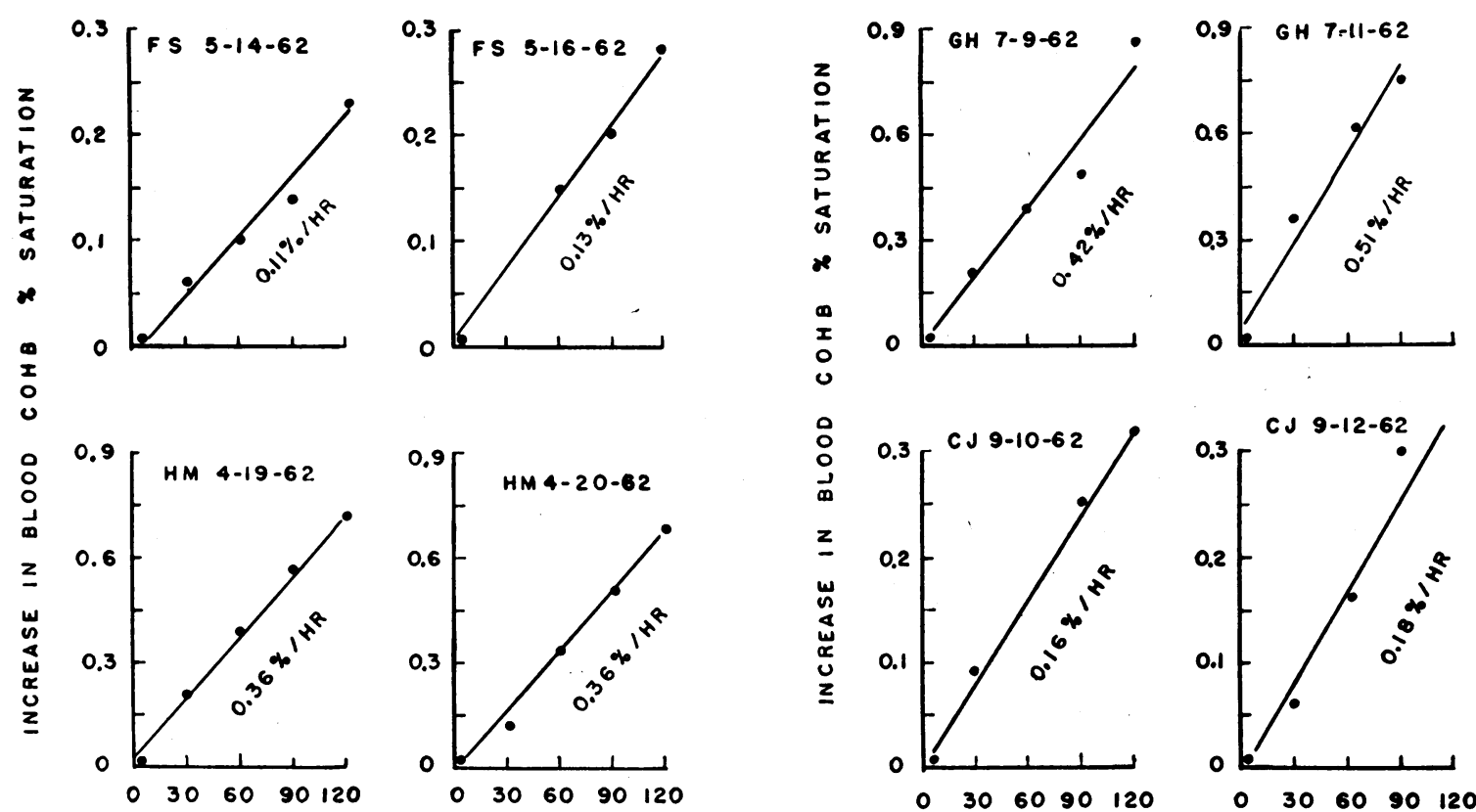

TIME IN MINUTES

TIME IN MINUTES

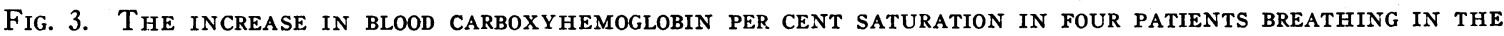
REBREATHING SYSTEM. This Figure shows the actual measured data and demonstrates the precision with which the rate of increase in blood carboxyhemoglobin can be determined. These duplicate studies were performed at 1- to 2day intervals. The regression lines were drawn by "least squares." The rate of CO production is calculated from these data and $\mathrm{CO}$ dilution in the body (5).

to $3.18 \mathrm{ml}$ per hour or 31 to $143 \mu$ moles per hour. Normal $V$ co is $18.7 \pm 0.8 \mu$ moles per hour (SE) (5). Vco was estimated in five patients on two occasions 1 to 2 days apart. Vco varied only $\pm 4.5 \mu$ moles per hour (SD) in the duplicate studies, and $[\mathrm{COHb}]$ varied $\pm 0.35 \%$ (SD). Figure 3 shows the increase in blood [COHb] in four patients studied on two occasions and illustrates the reproducibility and precision of the method.

Vco is compared to Vheme in Figure 4, where both are plotted in micromoles per hour. The data obtained from the patients with hemolytic anemia are plotted in closed circles, and the average $\mathrm{Vco}$ and calculated Vheme in ten normal supine male subjects at rest (5) are depicted by the filled square. The slope of the regression line is 1.04. The correlation coefficient is +0.94 .

The ratio of Vco to Vheme is listed in Table II for each study. This ratio varied from 0.99 to 1.92 , averaging $1.40 \pm 0.10(\mathrm{SE})$.

The relationship between venous blood [ $\mathrm{COHb}]$ and Vheme is plotted in Figure 5. The correlation coefficient between these variables is +0.59 .

\section{Discussion}

The rebreathing system developed for this study has made the measurement of Vco clinically feasible. Only two of the first twenty patients studied were not able to complete the procedure: one was a 70-year-old man with arteriosclerotic heart disease who could not lie flat as required with the present equipment.

In this study elevated $\mathrm{Vco}$ and blood [COHb] were found in seven patients with hemolytic anemia. The finding of elevated $[\mathrm{COHb}]$ in these patients confirms the report of Engstedt (10), and the elevated Vco demonstrates that the elevated $[\mathrm{COHb}]$ in patients with hemolytic anemia is actually a result of increased $\mathrm{CO}$ production. Rather poor correlation between the venous blood $[\mathrm{COHb}]$ level and Vheme was found $(r=0.59)$ in this study. The explanation for this finding appears to be that the blood [COHb] does not closely reflect the Vco. It has been shown in a previous publication (11) that $[\mathrm{COHb}]$ is influenced by the physiological processes that determine excretion of $\mathrm{CO}$ via the lungs, and by the quantity of $\mathrm{CO}$ in 
inspired air, as well as by Vco. In that study $\mathrm{Vco}$ and venous blood [COHb] were compared in 13 experiments, including the eight in the present investigation, and a correlation of +0.62 was found, a value similar to the correlation found here between Vheme and [COHb]. Since the relationship between Vheme and [COHb] cannot be closer than $\mathrm{V}$ co to [COHb], the venous blood $[\mathrm{COHb}]$ measurements appear to be a relatively imprecise index of red cell survival.

In the present study those patients with the shortest red cell survival times had the highest Vco values, suggesting the Vco might be used to quantitate red cell destruction rates. Since the error in the Vco measurement is very small (less than $5 \%$ of total Vco in these patients), the precision with which erythrocyte destruction could be quantitated would depend on $a$ ) whether CO was produced as a result of processes other than catabolism of hemoglobin in significant amounts and $b$ ) whether the molar yield of heme to $\mathrm{CO}$

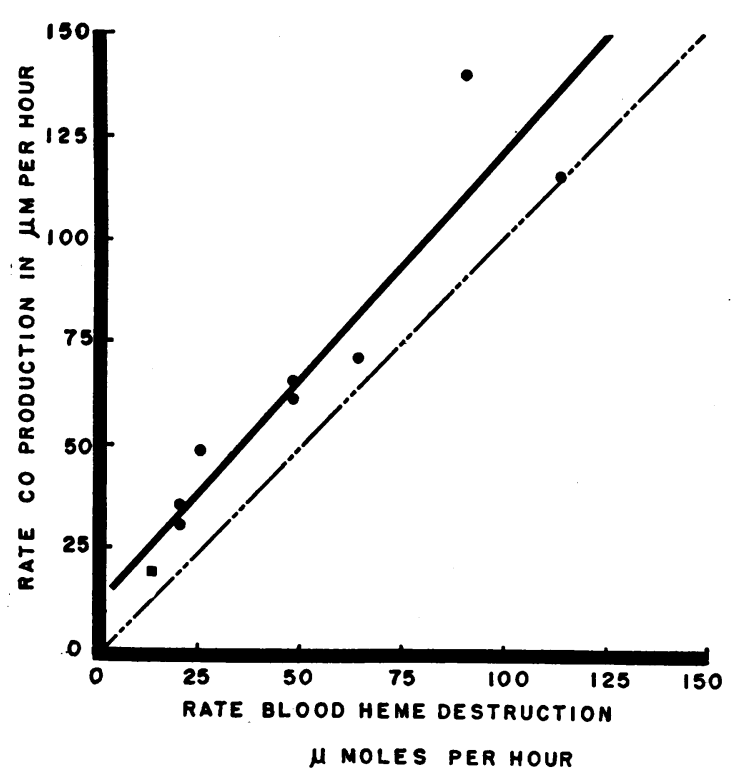

Fig. 4. COMPaRison OF THE RATE OF CO PRODUCTION AND RATE OF BLOOD HEME CATABOLISM IN PATIENTS WITH HEMOLYTIC ANEMIA. Hemolytic patients, closed circles; average value in ten normal male subjects, closed square (5). Rate of CO production was measured directly; rate of circulating heme catabolism was calculated from ${ }^{51} \mathrm{Cr}$-labeled erythrocyte decay curves. The solid line is a least squares regression line and was drawn through the "hemolytic" data. This regression line has a slope of 1.04. The interrupted line is drawn for a molar ratio of $\mathrm{Vco} / \mathrm{Vheme}$ equal to unity.

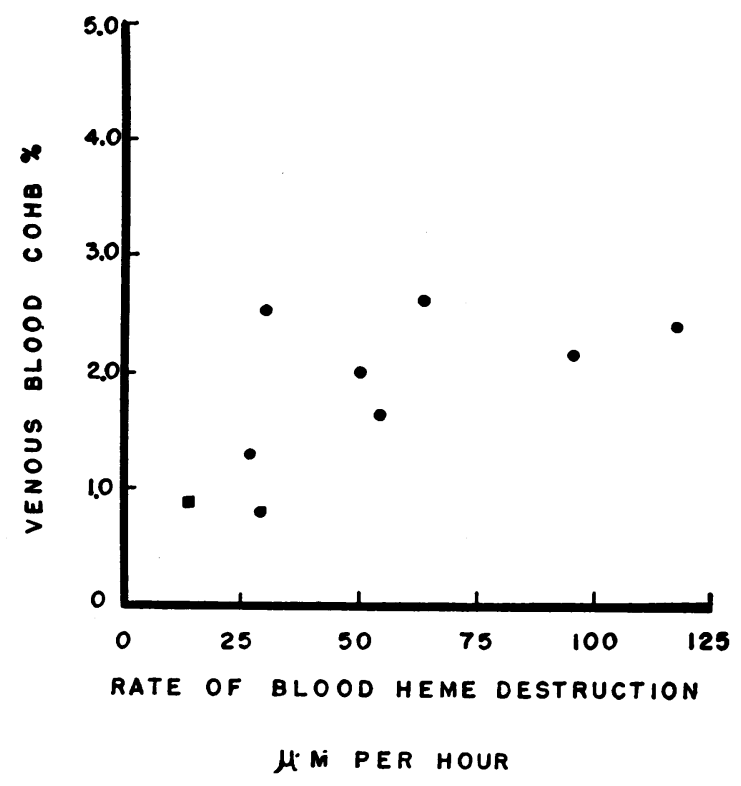

Fig. 5. COMPARISON OF VENOUS BLOOD CARBOXYHEMOGLOBIN PER CENT SATURATION AND THE RATE OF BLOOD HEME DESTRUCTION IN PATIENTS WITH HEMOLYTIC ANEMIA. Hemolytic data expressed in closed circles; average of ten normal subjects as closed square.

varied when the rate of hemoglobin catabolism was markedly increased.

Evidence is available that $\mathrm{CO}$ arises from processes other than circulating hemoglobin catabolism. In normal man approximately $20 \%$ of the Vco cannot be explained on the basis of destruction of hemoglobin from circulating erythrocytes (5). It is of interest that this "extra" $\mathrm{CO}$ is of the same magnitude as the "extra" stercobilin, which does not arise from circulating hemoglobin (19). It has recently been shown (20), that ${ }^{14} \mathrm{CO}$ appears in the expired air of humans shortly after the administration of glycine- $2-{ }^{14} \mathrm{C}$ and that the $\mathrm{CO}$ specific activity parallels that in bile pigment. These findings suggest a common molecular origin or origins for extra $\mathrm{CO}$ and extra bile pigment. Extra bile pigment, sometimes called "shunt" bile pigment, is thought to originate as a result of ineffective erythropoiesis (catabolism of immature erythrocytes in the bone marrow, or short-lived cells in the circulation) or as a by-product of porphyrin metabolism in the liver, or both (19, 21-23). It would be expected in patients with hemolytic anemia that the quantity of $\mathrm{CO}$ originating from cataholism of erythrocytes might be very large compared to that originating from these 
other sources, since the turnover of erythrocytes is so rapid.

To determine the per cent of total $\mathrm{CO}$ production arising from destruction of circulating erythrocytes in our patients, we estimated the rate of erythrocyte hemoglobin catabolism from ${ }^{51} \mathrm{Cr}$-labeled red blood cell measurements and compared this value, expressed as Vheme, with Vco. The estimation of Vheme from ${ }^{51} \mathrm{Cr}$ curves has many inherent errors. It requires an assumption regarding the mechanism of hemolysis and has uncertainties regarding $a$ ) elution of chromate from the labeled erythrocytes and $b$ ) steady state. The calculation of Vheme is in addition affected by errors in measuring total red blood cell mass; however, this error cancels out in the comparison of Vheme and Vco, since the red blood cell mass measurement is used in the calculation of $\mathrm{V}$ co as well.

In all the patients the curve of disappearance of ${ }^{51} \mathrm{Cr}$ from the blood was exponential, and it therefore appeared that the hemolytic mechanism was random. Six of the seven patients had either S-S disease or autoimmune hemolytic anemia, and in these conditions others have reported that red cell destruction is random $(24,25)$. We, therefore, assumed that destruction was random in all the patients. The error from some degree of nonrandom destruction in these patients would be small; for example, if one-half of the red cells were destroyed in a nonrandom fashion, assuming a random mechanism would lead to an overestimation of Vheme of only $12 \%$.

The recent study of Cline and Berlin (15) has made it possible to estimate errors in ${ }^{51} \mathrm{Cr}$ red blood cell survival measurements arising from uncertainty regarding the rate of elution of the label from the injected cells. These investigators measured decay curves of erythrocytes labeled simultaneously with ${ }^{32}$ diisopropyl fluorophosphate, ${ }^{14} \mathrm{C}$, and ${ }^{51} \mathrm{Cr}$ in 38 patients who had a variety of hematological diseases. It was assumed that the difference in decay rates between ${ }^{51} \mathrm{Cr}$ and the other labels was due to chromium elution. The rate of elution was found to be constant in most of the patients, was not related to the rate of hemolysis or the disease, and averaged $1.29 \%$ per day. We have calculated the standard deviation from the data presented by Cline and Berlin in this paper and found it to be $\pm 0.42 \%$ per day. This un- certainty in chromate elution rate is relatively small compared to our average rate decrease in ${ }^{51} \mathrm{Cr}$ radioactivity of $7.6 \%$ per day; the average error in Vheme resulting from variation in elution rates should be considerably less than $10 \%$. Even if any of our patients were at the extremes of the rates of chromium elution reported by Cline and Berlin, error in calculated Vheme would be less than $\pm 15 \%$ of total Vheme.

It is not possible to assess the error due to possible variations in the rate of erythrocyte destruction from day to day. The constant hemoglobin values and the close agreement of duplicate Vco measurements suggest the patients were in a steady state.

From these considerations the error in Vheme is estimated to be approximately \pm 6 to $8 \mu$ moles per hour. Most of these errors should be random and thus cause scatter of points in Figure 4. This estimate of the error in Vheme appears to be in the correct range, since the scatter about the regression line in Figure 4 averages approximately 8 moles per hour. The error in measurement of Vco is only approximately $\pm 3 \mu$ moles per hour, so it would appear that most of the scatter found in this Figure is a result of errors in the calculation of Vheme.

If the average value of $1.29 \%$ per day used in the correction for elution is in error, or if finite cell destruction was significant in our patients, a consistent error would result that would alter the regression line in Figure 4. Both of these possibilities appear to be very unlikely as discussed above.

If 1 mole of $\mathrm{CO}$ is produced from the destruction of 1 mole of heme, the data in Table II and Figure 4 show that an average of $74 \%$ of the $\mathrm{CO}$ produced arises from the destruction of circulating heme, whereas the remainder arises from other sources. This extra $\mathrm{CO}$ appears not to be an artefact. It cannot be explained on the basis of error in the calculation of Vheme. The extra $\mathrm{CO}$ is most likely the result of the same processes that yield extra $\mathrm{CO}$ in normal man. The absolute amount of extra $\mathrm{CO}$ is considerably greater than in normal man, suggesting that this fraction may arise primarily as a result of ineffective erythropoiesis. This concept is supported by the study of Gray and Scott (21), who stimulated erythropoiesis in one man by hemorrhage and found an 
increase in shunt bile pigment. Furthermore, in patients with sickle cell anemia (26) the plasma radioiron turnover ratio is increased followed by reduced red cell radioiron incorporation, as is seen in patients with the ineffective erythropoiesis syndrome. It seems unlikely that the extra $\mathrm{CO}$ found in our patients could be explained on the basis of folic acid deficiency. The serum folic acid levels and quantities of histidine metabolites in the urine were found to be normal in three of four patients where these measurements were performed as indicated in Table I.

Estimation of mean erythrocyte life-span from $C O$ production. The mean erythrocyte life-span (MLS) can be considered to be equal to the total body hemoglobin $\left(T_{\text {heme }}\right)$ divided by the quantity of hemoglobin destroyed per day if a steady state exists where the rate of hemoglobin destruction equals the rate of production. Since $\mathrm{CO}$ is probably produced in a molar ratio to blood heme catabolized in these patients, the following relationship should exist: $\mathrm{MLS}=\mathrm{T}_{\text {heme }}$ (micromoles)/ $\mathrm{Vco}$ (micromoles per day). In Figure 6 is shown the relationship of MLS calculated from $\mathrm{Vco}$, to MLS calculated from the ${ }^{51} \mathrm{Cr}$ red cell survival studies, where MLS $=1 / \mathrm{k}^{\prime} \times 100$. The points plotted in this Figure are all close to the least squares regression line. The slope of this line is 0.6 instead of 1.0 because of the extra $\mathrm{CO}$ production already discussed.

Because of the extra CO fraction, MLS should be calculated from $\mathrm{V} c 0$ as above, and then the "actual" life-span can be read from the abscissa in Figure 6. MLS can be computed from the Vco in this manner in our series with an error of only \pm 3 days compared to the chromium method.

If most of the extra $\mathrm{CO}$ originates as a result of ineffective erythropoiesis, calculation of erythrocyte life-span from $\mathrm{V}$ co without correction might indicate the average life-span of all erythrocytes, not just those labeled in the circulation. The mean erythrocyte life-span calculated from Vco without correction for extra $\mathrm{CO}$ may also prove to be a most useful determination when compared with results of measurements obtained by labeling circulating erythrocytes with radioactive tracers.

\section{Summary}

We have investigated the relationship of endogenous carbon monoxide production to red blood

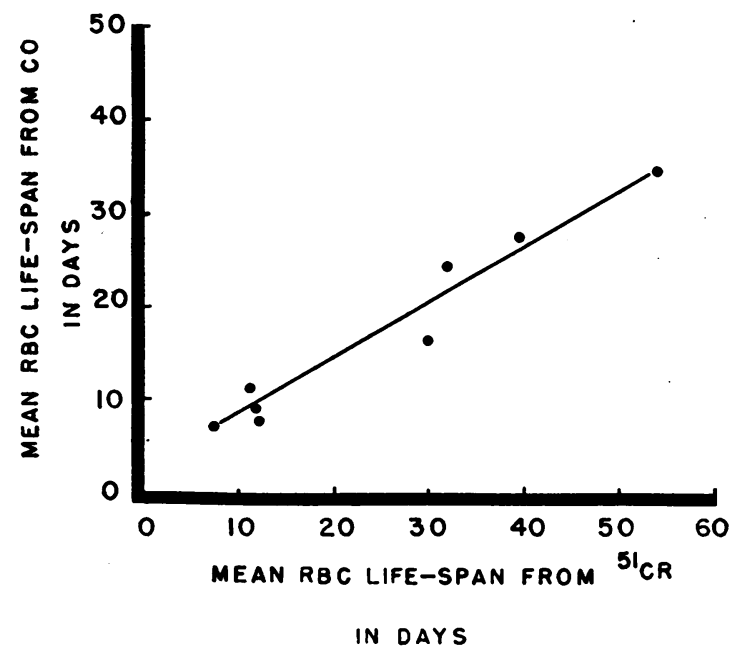

Fig. 6. COMPARISON OF MEAN ERYTHROCYTE LIFE-SPANS CALCUlated From (Y) THE RATE OF CO PRODUCTION AND (X) FROM BLOOD RADIOCHROMATE DECAY CURVES. RBC = red blood cells.

cell and hemoglobin catabolism in seven patients with hemolytic anemia. The rate of carbon monoxide production was markedly elevated in all of the patients. The rate of carbon monoxide production was found to correlate closely with the rate of blood heme destruction calculated from radiochromate red blood cell labeling studies $(r=$ $+0.94)$. Greater amounts of carbon monoxide were produced in six of eight studies than could be explained on the basis of blood heme catabolism. The average molar ratio was $1.41 \pm 0.28$ (SD). We suggest that the fraction of $\mathrm{CO}$ apparently not explainable on the basis of circulating hemoglobin catabolism, "extra $\mathrm{CO}$," is a by-product of the metabolic processes that cause "shunt" bile pigment. Mean erythrocyte life-spans can be calculated from the rate of carbon monoxide production corrected for extra $\mathrm{CO}$ with an error of \pm 3 days (SD).

\section{Acknowledgments}

We gratefully acknowledge the expert technical assistance of Robert Ersek, Dolores Thyrum, Mary Friedmann, and Irving Nagleberg and the advice and cooperation of Dr. Robert E. Forster.

\section{References}

1. Lester, R., and R. Schmid. Bilirubin metabolism. New Engl. J. Med. 1964, 270, 779.

2. Cruz, W. O., W. B. Hawkins, and G. H. Whipple. Acetylphenylhydrazine anemia. 2. Bile pigment 
elimination and new hemoglobin reconstruction in the bile fistula dog. Amer. J. med. Sci. 1942, 203, 848.

3. Sjöstrand, T. Endogenous formation of carbon monoxide in man under normal and pathological conditions. Scand. J. clin. Lab. Invest. 1949, 1, 201.

4. Sjöstrand, T. Endogenous formation of carbon monoxide. The $\mathrm{CO}$ concentration in the inspired and expired air of hospital patients. Acta physiol. scand. 1951, 22, 137.

5. Coburn, R. F., W. S. Blakemore, and R. E. Forster. Endogenous carbon monoxide production in man. J. clin. Invest. 1963, 42, 1172.

6. Coburn, R. F., W. J. Williams, and R. E. Forster. Effect of erythrocyte destruction on carbon monoxide production in man. J. clin. Invest. 1964, 43, 1098.

7. Sjöstrand, T. The in vitro formation of carbon monoxide in blood. Acta physiol. scand. 1952, 24, 314.

8. Sjöstrand, $T$. The formation of carbon monoxide by in vitro decomposition of haemoglobin in bile pigments. Acta physiol. scand. 1952, 26, 328.

9. Coburn, R. F., W. J. Williams, S. B. Kahn, G. D. Ludwig, and R. E. Forster. Endogenous CO production in dogs. Fed. Proc. 1964, 23, 469.

10. Engstedt, L. Endogenous formation of carbon monoxide in hemolytic disease with special regard to quantitative comparisons to other hemolytic indices. Acta med. scand. 1957 (suppl. 332), 159.

11. Coburn, R. F., R. E. Forster, and P. B. Kane. Considerations of the physiological variables that determine the blood carboxyhemoglobin concentration in man. J. clin. Invest. 1965, 44, 1899.

12. Coburn, R. F., G. K. Danielson, W. S. Blakemore, and R. E. Forster, II. Carbon monoxide in blood: analytical method and sources of error. J. appl. Physiol. 1964, 19, 510.

13. Luomanmäki, K., and R. F. Coburn. Unpublished observations.
14. Read, R. C. Studies of red-cell volume and turnover using radiochromium. Description of a new "closed" method of red-cell-volume measurement. New Engl. J. Med. 1954, 250, 1021.

15. Cline, M. J., and N. I. Berlin. The red cell chromium elution rate in patients with some hematologic diseases. Blood 1963, 21, 63.

16. Sjöstrand, T. A method for the determination of the total haemoglobin content of the body. Acta physiol. scand. 1949, 16, 211.

17. Herbert, V. The assay and nature of folic acid activity in human serum. J. clin. Invest. 1961, 40, 81.

18. Chanarin, I., and M. C. Bennett. A spectrophotometric method for estimating formimino-glutamic acid and urocanic acid. Brit. med. J. 1962, 1, 27.

19. London, I. M., R. West, D. Shemin, and D. Rittenberg. On the origin of bile pigment in normal man. J. biol. Chem. 1950, 184, 351.

20. White, P., R. F. Coburn, W. J. Williams, M. I. Goldwein, M. L. Rother, and B. C. Shafer. Carbon monoxide production associated with ineffective erythropoiesis (abstract). Blood 1964, 24, 845.

21. Gray, C. H., and J. J. Scott. The effect of haemorrhage on the incorporation of $\left[\alpha-{ }^{14} \mathrm{C}\right]$ glycine into stercobilin. Biochem. J. 1959, 71, 38.

22. Israels, L. G., T. Yamamoto, J. Skanderbeg, and A. Zipursky. Shunt bilirubin; evidence for two components. Science 1963, 139, 1054.

23. London, I. M., and R. West. The formation of bile pigment in pernicious anemia. J. biol. Chem. 1950, 184, 359.

24. James, G. W., III, and L. D. Abbott, Jr. Erythrocyte destruction in sickle-cell anemia: simultaneous $\mathrm{N}^{15}$-hemin and $\mathrm{N}^{15}$-stercobilin studies. Proc. Soc. exp. Biol. (N. Y.) 1955, 88, 398.

25. Brown, G. M., O. C. Hayward, E. O. Powell, and L. J. Witts. The destruction of transfused erythrocytes in anaemia. J. Path. Bact. 1944, 56, 81.

26. McCurdy, P. R. Erythrokinetics in abnormal hemoglobin syndromes. Blood 1962, 20, 686. 